\section{Estudo \\ CoDebate}

em Testão

Plamejamento
Revista Estudo \& Debate, Lajeado, v. 26, n. 1, 2019. ISSN 1983-036X

DOI: http://dx.doi.org/10.22410/issn.1983-036X.v26i1a2019.1895

\title{
POBREZA MULTIDIMENSIONAL E SEUS DETERMINANTES: UMA ANÁLISE ECONOMÉTRICA PARA OS ESTADOS BRASILEIROS COM MENOR E MAIOR IDH
}

\author{
Caroline Lucion Puchale ${ }^{1}$, Ohanna Larissa Fraga Pereira ${ }^{2}$, Clailton Ataídes de Freitas ${ }^{3}$
}

\begin{abstract}
Resumo: A visão de progresso social modificou-se desde a publicação do primeiro Relatório de Desenvolvimento Humano em 1990. A partir de entâo, fatores como a pobreza tornou-se extremamente importante para a mediçáo do desenvolvimento humano das naçóes. Tal fenômeno possui muitos conceitos que foram sendo formulados ao longo do tempo, desde formas unidimensionais de mediçáa, a partir da renda monetária, até uma abordagem multidimensional, agregando várias dimensôes que melhor explicam as privaçôes sofridas pelos indivíduos. Entretanto, poucos estudos têm abordado o problema da pobreza na forma multidimensional através de métodos econométricos. Assim, o objetivo deste estudo é averiguar os fatores, além da renda, que são determinantes da pobreza dita multidimensional nos estados de maior e menor IDH do Brasil, São Paulo e Alagoas, respectivamente. $\mathrm{O}$ estudo parte de uma análise econométrica feita através da estimação de um modelo de dados em painel, com base de dados captada no Atlas do Desenvolvimento Humano para os anos dos três censos. Os resultados encontrados corroboram com a literatura, indicando que outros fatores, além da renda monetária, como educaçáo, saúde e condiçôes de moradia, são determinantes para o nível de pobreza desses estados, confirmando o caráter multifacetado desse fenômeno.
\end{abstract}

Palavras-chave: Determinantes da Pobreza Multidimensional; Desenvolvimento Humano; Evolução do Conceito de Pobreza; Dados em Painel.

1 Bacharela em Ciências Econômicas pela Universidade Federal de Santa Maria (UFSM). Mestre em Economia e Desenvolvimento da Universidade Federal de Santa Maria (UFSM). Atualmente é doutoranda no Programa de Pós-Graduaçáo em Economia com ênfase em economia aplicada da Universidade Federal do Rio Grande do Sul (UFRGS).

2 Bacharela em Ciências Econômicas pela Universidade Federal do Ceará (UFC). Mestre em Economia e Desenvolvimento da Universidade Federal de Santa Maria (UFSM). Atualmente é doutoranda no Programa de Pós-Graduação em Desenvolvimento Econômico da Universidade Estadual de Campinas (Unicamp).

3 Graduaçáo em Ciências Econômicas pela Universidade Federal de Uberlândia (UFU). Mestrado em Economia Rural pela Universidade Federal do Rio Grande do Sul (UFRGS). Doutorado em Ciências (Economia Aplicada) pela Escola Superior de Agricultura Luíz de Queiroz da Universidade de São Paulo (ESALQ/USP). Pós-Doutorado em Estatística e Experimentação Agropecuária pelo Departamento de Ciências Exatas da Universidade Federal de Lavras (UFLA). Atualmente, é Professor Titular da Universidade Federal de Santa Maria - UFSM e dos Programas de Pós-Graduação em Economia e Desenvolvimento PPGE\&D e Pós-Graduação em Gestão de Organizaçôes Públicas - PPGOP. 


\title{
MULTIDIMENSIONAL POVERTY AND THEIR DETERMINANTS: AN ECONOMETRIC ANALYSIS FOR BRAZILIAN STATES WITH LOWER AND HIGHER HDI
}

\begin{abstract}
The vision of social progress has changed since the publication of the first Human Development Report in 1990. Since then, factors such as poverty have become extremely important in measuring the human development of nations. This phenomenon has many concepts that have been formulated over time, ranging from one-dimensional forms of measurement, from monetary income to a multidimensional approach, adding several dimensions that best explain the privations suffered by individuals. However, few studies have addressed the problem of poverty in multidimensional form through econometric methods. Thus, the objective of this study is to ascertain the factors, besides income, that are determinants of the multidimensional poverty, in the states of major and minor HDI of Brazil, São Paulo and Alagoas, respectively. The study is based on an econometric analysis made through the estimation of a panel data model, based on data collected in the Atlas of Human Development for the years of the three censuses. The results corroborate with the literature, indicating that factors other than monetary income, such as education, health and housing conditions, are determinant for the level of poverty in these states, confirming the multifaceted nature of this phenomenon.
\end{abstract}

Keywords: Determinants of Multidimensional Poverty; Human Development; Evolution of the Poverty Concept; Panel Data.

\section{Introdução}

A visão de progresso social modificou-se profundamente desde a publicação do Relatório de Desenvolvimento Humano (RDH) na década de 90. A partir de então, a perspectiva dos formuladores de políticas públicas, economistas, cientistas sociais e da sociedade como um todo, expandiu-se para um panorama que abrange uma análise sistemática de um conjunto de informaçôes acerca das condiçóes de vida dos seres humanos. Fatores como a desigualdade, a insegurança e, sobretudo, a pobreza, tornaram-se ainda mais importantes para a medição de desenvolvimento humano das nações (PNUD, 2010).

No Brasil, essa perspectiva mais ampla do progresso social também difundiu-se entre os estudiosos, de forma que Graziano (2001) chegou a afirmar que não há estratégia de desenvolvimento no país que não vise o combate à pobreza. Contudo, ressalta-se que a pobreza é um fenômeno de difícil definição e quantificação. De acordo com Townsend (2006), vários conceitos e formas de medição da pobreza foram desenvolvidos, entretanto, esses critérios, apoiados, sobretudo, na renda, não conseguiam expressar todas as facetas do real grau de privação dos indivíduos pobres, pois a renda em si já é um conceito tâo problemático quanto o da pobreza.

$\mathrm{O}$ autor destaca que a partir de 1880 surgiram três concepções da pobreza: de subsistência, de necessidades básicas e de privação relativas (TOWSEND, 2006). Ao longo do tempo, foram sendo incorporadas visóes que englobava outras dimensóes de privação além da renda monetária, mas apenas por volta dos anos 2000 emergiu uma importante abordagem sobre esse tema nas obras de Sen (2013): a Abordagem das Capacitaçóes. Em sua conceituação, o autor explica que pobreza é algo complexo e agregador de multifatores que vão além da renda monetária; e retrata a maneira pela qual os agentes podem ser considerados privados de levar a vida que desejam, sendo através de fatores políticos, sociais ou econômicos (SEN, 2013). 
Dentro dessa perspectiva, em 2000, os Estados-membros da Organização das Nações Unidas (ONU) estipularam, para o Brasil - através dos Objetivos do Milênio - a meta nacional de redução da porcentagem de pobres em 1/4 do que era em 1994, alcançada em 2008; e a meta de redução da pobreza extrema até a metade do que era em 1990, a qual foi atingida em 2002. No ano de 2015, a ONU passou a reconhecer a erradicação da pobreza, manifestada em todas as dimensóes, como o principal desafio das naçóes (NAÇÕES UNIDAS, 2015).

Tendo essa abordagem da pobreza como alicerce e entendendo sua importância para o alcance de maiores níveis de desenvolvimento humano das naçóes, este estudo propóe-se a responder: "Quais foram os principais determinantes da pobreza multidimensional nos estados brasileiro de menor (Alagoas) e maior IDH ${ }^{4}$ (São Paulo) nos anos censitários de 1991, 2000 e 2010?" Para isso, construiu-se o objetivo primordial de averiguar quais fatores, além da renda, foram determinantes da pobreza mulifacetada em São Paulo e Alagoas.

A escolha dos dois estados pauta-se na ideia de que o desenvolvimento dos países relaciona-se em grande medida com a pobreza, e apesar de o Brasil ter experimentado ao longo dos últimos anos, uma grande reduçáo no número de pobres, isso náo ocorreu uniformemente entre todos os seus estados (IPEA, 2010). Portanto, torna-se relevante encontrar, através de um comparativo entre as unidades federativas com maior e menor índice de desenvolvimento humano, os determinantes da pobreza multidimensional, procurando identificar semelhanças ou diferenças entre as facetas de suas pobrezas. A medida de desenvolvimento utilizada foi o Índice de Desenvolvimento Humano (IDH), que Romero (2006) ressalta como um dos indicadores que mede a pobreza e o desenvolvimento de forma mais eficiente, por isso a escolha dos estados com maior e menor IDH para esse estudo.

Destaca-se que este trabalho tem como referência o estudo de Martins e Wink (2013), que procurou identificar a pobreza multidimensional no estado do Rio Grande do Sul tendo como um dos métodos aplicados o de Mínimos Quadrados Ordinários (MQO) apenas para o ano de 2010. Entretanto, para alcançar o objetivo aqui proposto, o presente artigo utilizou-se de uma metodologia de análise econométrica mais complexa, de dados em painel, com base de dados captada no Atlas do Desenvolvimento Humano no Brasil para os três Censos (1991, 2000 e 2010) englobando um maior conjunto de variáveis.

\section{Referencial teórico}

\subsection{Desenvolvimento Humano}

O estudo do desenvolvimento humano passa a ter maior enfoque em 1990, quando foi lançado o primeiro RDH elaborado pelo PNUD 5 . O PNUD (2010) passa a considerar as pessoas como a verdadeira riqueza das naçóes e, por isso, o objetivo primordial do

\footnotetext{
4 Índice de Desenvolvimento Humano.

5 Programa das Nações Unidas para o Desenvolvimento.
} 
desenvolvimento torna-se promover ambientes com maiores possibilidades de escolhas aos indivíduos, onde eles possam desfrutar de uma vida saudável, longa e com acesso ao conhecimento, ou seja, que possam viver com dignidade. Sen (2013) ressalta que o estudo do desenvolvimento humano passou a sugerir uma análise das condições de vida dos indivíduos em cada sociedade e de suas liberdades substantivas. Já em 1990, o RDH trazia temas relacionados às privaçóes dos indivíduos, à desigualdade entre os países e à capacitação dos agentes, assuntos que vão ao encontro da literatura de Amartya Sen (PNUD, 2010).

O fenômeno do desenvolvimento humano agrega uma infinidade de fatores que pertencem a processos não só econômicos como de ordem social e subjetiva. Seu desafio principal é, sobretudo, aumentar as liberdades individuais e dar espaço para que as capacidades de realização se desenvolvam. Constantemente os indivíduos se aprisionam em limitaçóes, as quais os impedem de exercer a vida que desejam em sociedade. Barreiras formadas, muitas vezes, em razão das circunstâncias nas quais os agentes nascem inseridos. Essa observação demonstra que a análise e a conceituação do desenvolvimento humano enfrenta questôes táo complexas quanto a pobreza (SEN, 1993).

O desenvolvimento deve fornecer oportunidades a cada indivíduo através da formação de capacidades humanas por meio do acesso à saúde, à educação, às condiçóes adequadas de moradia e etc., e, dessa forma, melhorar o padrão de vida das pessoas. Logo, esse novo conceito diferencia-se da concepçáo de desenvolvimento utilizada até então, em que o progresso de um país era medido exclusivamente pelo Produto Interno Bruto per capita (PIB per capita) (VAZ \& SILVA, 2013).

Junto à essa teoria, surge a necessidade de mensurar de forma prática esse fenômeno. Buscou-se um instrumento de mensuração tão objetivo quanto o PIB, utilizado anteriormente. Surge, entáo, no RDH de 1990, o IDH, pautado, na versão atual, em três dimensōes principais e quatro indicadores, como mostra a Figura 1.

Figura 1 - Dimensóes e Indicadores do IDH

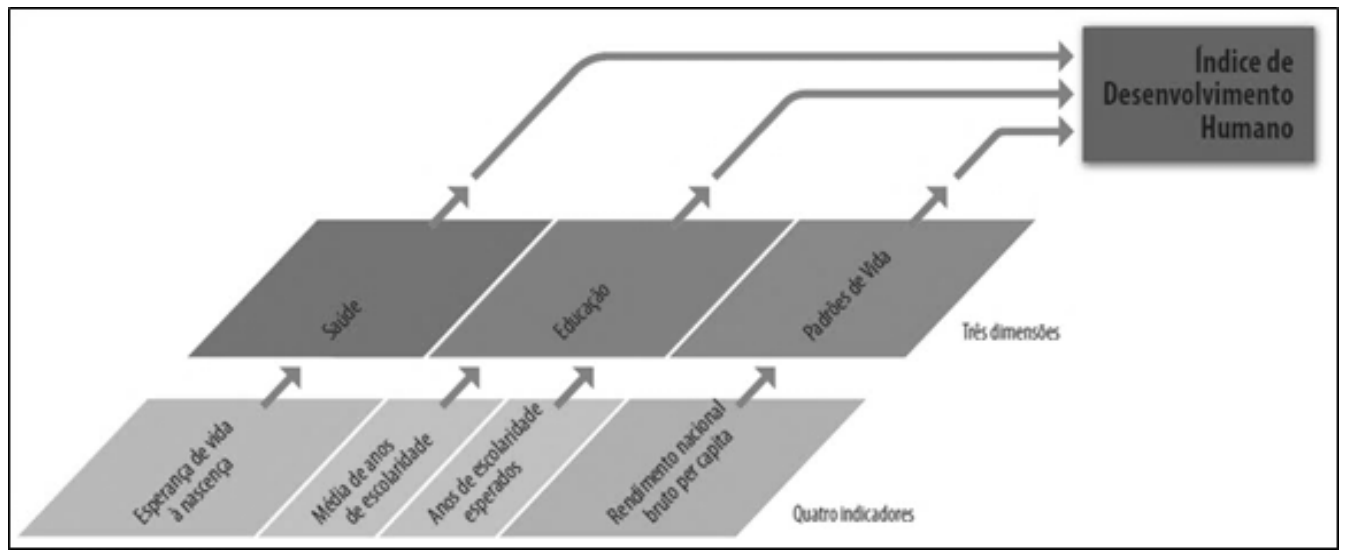

Fonte: PNUD (2010, p. 13).

Segundo Guimarães e Jannuzzi (2005), o caráter multivariado do IDH faz tratar o desenvolvimento humano de maneira mais completa que os chamados Indicadores 
de Primeira Geração, como o PIB per capita. Além disso, ele é considerado um índice compreensível, com metodologia simples e de fácil aplicação a diferentes realidades. Porém, não escapa às limitaçóes. Cardoso (1998) destaca que este índice estabelece padróes mínimos universais de qualidade de vida que devem valer para todos os países, não respeitando assim a cultura do país, as particularidades regionais, hábitos de consumo e até mesmo o grau de satisfação da população de dado local. Não se pode negar, todavia, que os avanços trazidos pelo IDH levam a um entendimento social mais amplo que a abordagem do crescimento econômico apenas centrada no PIB.

O caso do Brasil é particularmente interessante, pois o país como um todo apresentou melhorias significativas do IDH ao longo dos censos, mas seus estados apresentam níveis completamente diferentes de desenvolvimento. Além disso, a pobreza continua sendo um problema pertinente por todo o território, mas com dimensões diferentes de privação conforme muda o padráo de vida local (VAZ \& SILVA, 2003). Destaca-se que no Brasil, desde 1998, calcula-se o IDH à nível subnacional através do censo demográfico, chamando-o de Índice de Desenvolvimento Humano Municipal (IDHM), todavia ele segue as mesmas dimensóes e indicadores do IDH global, com mudanças muito pequenas (ORSI, 2009).

\subsection{Evolução do conceito de pobreza}

A compreensão do fenômeno da pobreza deve considerar a evolução do seu conceito no tempo, bem como suas raízes históricas. Conforme Codes (2008), logo nos primórdios do capitalismo a pobreza começou a ser discutida e a atrair interesses dos governantes e dirigentes das pequenas comunidades. Entretanto, foi com o advento da Revoluçáo Industrial que as primeiras políticas sociais passaram a ser desenvolvidas a fim de erradicar esse fenômeno. Os governantes de outrora pequenas instituiçóes (como igrejas) da Inglaterra e de outros países da Europa, começaram a desenvolver iniciativas para aliviar as situaçóes de miséria daqueles que pertenciam a essas localidades.

No século XIX, mais especificamente durante o período de industrialização, a miséria da classe trabalhadora alcançou grandes proporçóes, fazendo com que essas pequenas políticas sociais que ocorriam em instituições isoladas fossem insuficientes e, assim, a discussão sobre os meios de erradicar a pobreza começou a ganhar forma e volume, atingindo um nível macroeconômico (MESTRUM, 2002).

Percebe-se que os estudos da pobreza remontam de períodos distantes no tempo, mas continua sendo uma discussão instrumento de controvérsias, uma vez que ainda hoje não existe um consenso entre os estudiosos sobre sua análise e conceito científico. Como confirmado por Romão (1982, p. 356):

Não existe consenso entre os estudiosos da pobreza quanto à linha "ótima" da pobreza num sentido preciso, ou a uma medida relativa "ótima" no sentido de que melhor refletisse a posiçấo relativa dos pobres.

Entretanto, autores como Romão (1982), Crespo e Gurovitz (2002), Codes (2008), Martini et al. (2009) e entre outros, conseguiram estabelecer ao longo do tempo a existência de três noçóes iniciais de pobreza: absoluta, relativa e subjetiva. A forma mais difundida 
encontra-se na noção absoluta, encarada como a pobreza material, onde um indivíduo é considerado pobre quando não possui as condições mínimas para sobreviver, ou seja, não possui os requisitos mínimos para manter suas condições físicas, como por exemplo, estar bem nutrido. A percepção da pobreza relativa, segundo Romão (1982), advém da desigualdade na distribuição de renda, isto é, pobre é o indivíduo que não possui as mesmas oportunidades e condiçóes econômicas e sociais do restante da sociedade em que está inserido. Enquanto a noção de pobreza subjetiva, relaciona-se ao sentimento do indivíduo de considerar-se pobre, é a sensação de exclusão social (MARTINI et al., 2009).

Essas três noçóes iniciais de pobreza deram margem para o nascimento de quatro principais abordagens teóricas desse fenômeno que norteiam os trabalhos acerca desse fenômeno até os dias atuais. Algumas delas são medidas unidimensionais, enquanto outras agregam mais fatores que podem ser fontes de privação, dando origem à denominação da pobreza dita multidimensional (CODES, 2008).

Uma dessas concepçóes é a Pobreza de Subsistência, que teve origem em 1890 nos trabalhos de nutricionistas ingleses e predominou até a década de 1950, exercendo grande influência na Europa. Sua medida principal considerava apenas o PIB per capita e era muito quantificada através das linhas de indigência (TOWSEND, 2006). Essa abordagem considera que um indivíduo é pobre quando não possui recursos monetários suficientes para manter o mínimo de alimentos necessários para sua sobrevivência física, ou seja, quando o agente passa fome. Entretanto, é considerada uma conceituação extremamente limitada, pois, ao considerar apenas as necessidades físicas mais básicas do ser humano, ignora o fornecimento de serviços públicos essenciais. Além de desconsiderar as diferenças de aspectos ligados à nutrição e culinária das diferentes sociedades do mundo (CODES, 2008).

A segunda abordagem emerge a partir de 1970, e foi chamada de Pobreza de Necessidades Básicas. Sua visão amplia o leque de exigências de consumo das famílias, agregando os serviços de saúde, saneamento básico, educação, energia elétrica e entre outros fatores que avançam para a ideia de pobreza multidimensional. Nessa abordagem, o indivíduo não estará sob a linha de pobreza se, além de conseguir manter-se bem nutrido, também tiver acesso a bens sociais e econômicos (HICK, 2014). Devido sua ampliação na conceituação da pobreza, foi uma abordagem muito utilizada por grandes órgãos internacionais como aqueles que integram a Organização das Nações Unidas (ONU). Contudo, ainda possui limitaçóes, uma vez que, mesmo sendo uma uma ampliação da abordagem de subsistência, não incorpora valores éticos vinculados à questóes sociais como das diferenças entre grupos específicos de cidadãos, consistindo em análise que não agrega os meios científico, político e social de uma mesma sociedade. Desconsiderando, sobretudo, que as necessidades mudam conforme o tempo e a localidade dos indivíduos (SEN, 2000; SALAMA; DESTREMAU, 2001).

A terceira abordagem da pobreza denominou-se Privação Relativa, sua criação visava a expansão do número de indicadores considerados em termos sociais, materiais e de renda e a inclusão da concepção de que as privaçóes são mutáveis entre as localidades e no passar do tempo (TOWSEND, 1993). Dentro dessa abordagem, a pobreza é tida como uma comparação, considera-se pobre aquele que não possui condições de viver satisfatoriamente na sociedade na qual se insere (CODES, 2008). Uma das limitações desse conceito consiste 
em vincular completamente a pobreza à degeneração dos direitos de cidadania. Conforme Carvalho (2002), a cidadania inclui diversas dimensóes, mas nem sempre a obtenção de certos direitos conduzem ao exercício de outros também necessários. Ademais, a Privação Relativa inclui em sua mensuração uma linha de renda vinculada ao tamanho e tipo de família, utilizando-se ainda de fatores objetivos de medição que desvia o foco do indivíduo.

Foi devido a essas limitaçóes na evolução do pensamento da pobreza que emergiu a quarta concepçáo desse fenômeno: a Abordagem das Capacitaçóes de Amartya Sen. Na perspectiva do autor, a pobreza é entendida pela ótica do indivíduo. Considera que pobreza é a privação das capacidades básicas dos agentes e não sua escassez de renda. $\mathrm{O}$ fato de o indivíduo ser pobre, advém das privaçôes que ele sofre, sejam elas no acesso à saúde, à educação, aos direitos sociais ou civis, atingindo a capacidade do indivíduo de obter os recursos pretendidos e dificultando a possibilidade de o agente levar a vida que almeja em sociedade (SEN, 2013).

Conforme essa abordagem, a pessoa pode ter vários bens e recursos à sua disposição, mas, o fato de não conseguir obtê-los, já o torna privado, tanto por condições de saúde e moradia, quanto por questôes raciais e financeiras, por exemplo. Segundo Codes (2008), na perspectiva da privação de capacidades básicas, um indivíduo não passa fome porque não tem alimentos disponíveis, mas porque ele não tem capacidade de obtê-los. Como é afirmado pelo próprio Sen (2013, p. 123):

O que a perspectiva da capacidade faz na análise da pobreza é melhorar o entendimento da natureza e das causas da pobreza e privação, desviando a atenção principal dos meios (e de um meio específico que geralmente recebe atenção exclusiva, ou seja, a renda) para os fins que as pessoas têm razão para buscar e, correspondentemente, para as liberdades de poder alcançar esses fins.

As conceituaçôes anteriormente difundidas da pobreza passaram por abordagens tanto uni quanto multidimensionais, contudo, todas elas, de alguma maneira, davam maior enfoque à renda ou apenas nela apoiavam-se. Na literatura desenvolvida por Sen (2013), o autor admite que não se pode desprezar o fato de que um nível de renda baixo afeta as capacidades das pessoas e a renda é uma das principais privaçóes, sobretudo em países em desenvolvimento. Porém, ressalta que a perspectiva monetária deve ser encarada somente como um instrumento que fortalece a pobreza e não como o verdadeiro motivo que coloca os indivíduos neste estado (SANTOS; VILLATORO, 2018). Muito mais do que um agente não possuir renda, pior é não ter oportunidades (de moradia, saneamento básico, saúde, direitos civis e entre outros) para que possa inteirar sua realidade com dignidade. Desta forma, Crespo e Gurovitz (2002) concluem:

A pobreza deve ser entendida como a privação da vida que as pessoas realmente podem levar e das liberdades que elas realmente têm. A expansão das capacidades humanas enquadra-se justamente nesse ponto. Não se pode esquecer que o aumento das capacidades humanas tende a caminhar junto com a expansão das produtividades e do poder de auferir renda. Um aumento de capacidades ajuda direta e indiretamente a enriquecer a vida humana e a tornar as privaçóes humanas mais raras e menos crônicas. As relaçóes instrumentais, por mais importantes que sejam, não podem substituir a necessidade de uma compreensão básica da natureza e das características da pobreza. (CRESPO; GUROVITZ, 2002, p.6). 
A evolução da ideia de pobreza mostra que tal conceito libertou-se de uma visão totalmente unidimensional, para agregar multifatores, constituindo a conceituação da pobreza multidimensional (ALKIRE; OLDIGES; KANAGARATNAM, 2018). Contudo, em diversas localidades ainda não se conseguiu desenvolver uma medida que consiga agregar a subjetividade e a complexidade desse fenômeno através da Abordagem das Capacitaçôes. No Brasil, o banco de dados disponibilizado pelo IBGE ainda considera a pobreza apenas através da renda monetária, desconsiderando os diversos outros fatores capazes de medir a incidência desse fenômeno através do seu aspecto multidimensional.

\subsection{Evidências empíricas}

Vários estudos no Brasil e no mundo foram realizados analisando as várias faces da pobreza com diferentes abordagens metodológicas. Na esfera nacional, Martins e Wink Júnior (2013) buscaram caracterizar a extrema pobreza no Rio Grande do Sul para as áreas rural e urbana através de uma análise de cluster e do método econométrico de Mínimos Quadrados Ordinários. As dimensóes utilizadas foram: Pobreza Urbana, Pobreza Rural, Educação, Saúde e Saneamento, com dados retirados do DATASUS e do Censo Demográfico de 2010. Os resultados encontrados demonstraram o caráter multidimensional da pobreza em ambas as análises. A primeira mostrou que existe uma forte correlação entre municípios com altos percentuais de população abaixo da linha de pobreza, educação precária, condições de saúde deficientes e condiçóes de saneamento ineptas. A análise econométrica indicou que as variáveis educação, saneamento e saúde relacionam-se significativamente com a pobreza, quanto piores são as condiçōes dessas dimensōes, maiores os níveis de pobreza da região. Encontraram, ainda, que essa relação é ainda mais forte no meio rural.

Fahel, Teles e Caminhas (2016) criaram um Índice de Pobreza Multidimensional (IPM) para o Brasil visando analisar a incidência e a intensidade da pobreza no país. Os autores utilizaram o método Alkire e Foster, com dados retirados da PNAD ${ }^{6}$ de 2002, 2007 , 2012 e 2013. As dimensões analisadas foram Educação, medida pelos indicadores: anos de escolaridade e frequência escolar; Saúde, mensurada pelo indicador mortalidade infantil; e Padrão de Vida, medida pelos indicadores: combustível de cozinha, eletricidade, água, bens adquiridos, saneamento básico e tratamento do lixo. Os resultados indicaram uma redução do IPM no Brasil entre 2002 e 2013 devido, principalmente, aos indicadores da dimensão Educação. Porém, para as Regióes Nordeste e Norte, macrorregióes com pobreza multidimensional mais acentuada, é maior a contribuição dos indicadores de Serviços Básicos de Saneamento (lixo, esgoto e água). Encontraram, ainda, que todos os indicadores foram piores nas zonas rurais que nas zonas urbanas.

O estudo de Martins et al. (2019) mapeou e analisou a pobreza multidimensional nos municípios de Itabuna e Ilhéus, ambos no estado da Bahia. Para isso, realizaram o cálculo de um índice de pobreza multidimensional composto pelas dimensôes: Educação, medida pelo indicador pessoas não alfabetizadas; Saúde, mensurada através do indicador capacidade para se alimentar; e Padrão de Vida, composta pelos indicadores: eletricidade, abastecimento de

6 Pesquisa Nacional por Amostra de Domicílios. 
água, saneamento, coleta de lixo e aquisição de ativos. A base de dados foi retirada do Censo Demográfico de 2010 do IBGE. Os resultados indicaram que a incidência e a intensidade da pobreza se dispersa por todo o território dos municípios analisados, porém, constatou-se que ela concentra-se, principalmente, na zona rural. Entre as dimensóes analisadas, Padrão de Vida obteve maiores privaçóes em ambos os municípios, principalmente devido às deficiências nos serviços de esgotamento sanitário, destino do lixo e abastecimento de água.

No campo internacional, Diallo (2012) realizou um estudo em Guiné que objetivava constatar a pobreza multifacetada através do método de análise fuzzy. O autor considerou aspectos tanto monetários como náo monetários, utilizando como base de dados a Full Base Survey on Poverty Assessment (2002/2003). Os indicadores considerados foram: nível educacional, tipo de telhado e paredes externas da residência, tipo de banheiro, tipo de habitação, forma de abastecimento de água, tipo de combustível utilizado na cozinha, forma de iluminação utilizada na residência, despesas anuais por membro da família, índice de liquidez e compra de mercadorias duradouras. Os resultados demonstraram que os indicadores que compóem as dimensóes Educação, Condiçóes de Moradia, Infraestrutura e Posses de Bens foram os mais significativos ao explicar os níveis de pobreza, reiterando o caráter multidimensional desse fenômeno em Guiné. Constatou-se ainda, que as regiôes: N'Zérékoré, Faranah, Labé, Kankan e Mamou eram as mais privadas multidimensionalmente; e que metade da população guineana ainda era pobre no período analisado.

Wang e Wang (2016) realizaram um estudo com o propósito de quantificar e analisar a pobreza multidimensional nas áreas rurais da cidade de Hechi, localizada na região da República Popular da China. Os autores utilizaram o método Alkire Foster (AF) para quatro quatro dimensōes: Habitação, Saúde, Educação e Condições de Vida, as quais foram mensuradas por dez indicadores. Os dados foram retirados do Departamento Oficial de Alívio da Pobreza da cidade de Hechi, com informaçóes acerca das famílias rurais pobres referente ao ano de 2013. Como principal resultado, os autores verificaram que pobreza rural multidimensional tem aumentando significativamente por questôes de insegurança habitacional, saúde da família e analfabetismo dos adultos.

Santos e Villatoro (2018) criaram um Índice de Pobreza Multidimensional para a América Latina através do método Alkire e Foster para os anos de 2005 e 2012. Os autores incluíram indicadores tanto monetários como não monetários, que pudessem atualizar os limites de privação de indicadores tradicionais de necessidades básicas e, dessa forma, melhorar as condiçôes de comparação entre os 17 países investigados da região. Os dados foram retirados de pesquisas domiciliares realizadas nesses países e harmonizados pela $\mathrm{CEPAL}^{7}$, para que se tornassem o mais comparáveis possível. Treze indicadores agruparamse em cinco dimensóes principais, denominadas: Habitação, Serviços Básicos, Padrão de Vida, Educação e Emprego e Proteção Social. Os resultados indicaram uma redução significativa da pobreza na regiấo desde 2005 , contudo, cerca de $28 \%$ da populaçáo (159,224 milhôes de pessoas) ainda eram multidimensionalmente pobre em 2012. Dentre as dimensóes analisadas, Padrão de Vida lidera representando cerca de $30 \%$ da pobreza

7 Comissão Econômica para a América Latina e o Caribe. 
total, enquanto as quatro dimensôes restantes mantêm contribuiçáo semelhante, embora haja variações entre os países. Constatou-se, também, que as disparidades entre áreas rurais e urbanas permanecem.

\section{Metodologia}

O presente artigo possui natureza aplicada com enfoque explicativo, que, para Gil (2009), caracteriza-se pela busca da identificação dos fatores que determinam a ocorrência de determinado fenômeno. Desta maneira, o objetivo aqui proposto constitui-se da identificação dos determinantes da pobreza multidimensional nos estados brasileiros que apresentam maior e menor IDH: São Paulo e Alagoas, respectivamente. A mensuração dos fatores de privação realizou-se através de uma análise econométrica de dados em painel para os últimos três anos censitários.

\subsection{Base de dados}

A fonte de dados utilizada para a estimação do modelo econométrico foi retirada do Atlas do Desenvolvimento Humano, correspondente aos censos de 1991, 2000 e 2010. As variáveis utilizadas no modelo estão resumidas no Quadro 1.

Quadro 1 - Variáveis utilizadas no modelo econométrico

\begin{tabular}{|c|c|c|c|}
\hline Dimensão & Variável proxy & Sigla & $\begin{array}{c}\text { Sinais } \\
\text { Esperados }\end{array}$ \\
\hline Pobreza & Percentual do número de pobres* & Pobreza & $\begin{array}{c}\text { Variável } \\
\text { Dependente }\end{array}$ \\
\hline Renda & Índice de Gini & Renda & + \\
\hline Saúde & Mortalidade infantil & lnSaúde & + \\
\hline Educação & $\begin{array}{c}\text { Taxa de analfabetismo da população de 15 } \\
\text { anos ou mais }\end{array}$ & Educacao & + \\
\hline $\begin{array}{c}\text { Condiçáa de } \\
\text { Moradia }\end{array}$ & $\begin{array}{c}\text { Percentual da populaçáo que vive em } \\
\text { domicílios com banheiro e água encanada }\end{array}$ & CondMoradia & - \\
\hline
\end{tabular}

Fonte: Elaboração própria.

Nota: *São considerados pobres os indivíduos que possuem renda domiciliar per capita igual ou inferior a $\mathrm{R} \$ 140,00$ mensais)

Como exposto no quadro acima, foram consideradas quatro dimensóes para a mensuração da Pobreza, variável dependente medida pela proxy percentual do número de pobres. A primeira dimensão considerada foi Renda, quantificada pelo Índice de Gini. A renda possui grande importância na mensuração dos níveis de pobreza, pois segundo Sen (2013), é um dos instrumentos que fortalece o estado de miséria dos indivíduos. A utilização da proxy Índice de Gini para sua medição, justifica-se por ser uma medida de desigualdade de rendimentos que varia de zero a um, de forma que quanto mais próximo 
de um, mais alta é a desigualdade da população analisada e quanto mais próximo de zero, menor será essa desigualdade.

A dimensão Saúde foi mensurada pela proxy mortalidade infantil, indicador que, segundo a UNICEF (2013), pode ser combatido através de melhorias no acesso a serviços de saúde oferecidos à população, tais como: aprimoramento do atendimento materno, ampliação do número de vacinas, imunizaçóes e elaboração de programas de proteção social. $\mathrm{O}$ combate à privações nessa dimensão está vinculada, portanto, à redução da mortalidade infantil.

Quanto à dimensão Educação, optou-se pela sua mensuração através da taxa de analfabetismo. Essa dimensão é considerada de grande importância, pois a educação é o caminho para que os indivíduos saiam da condição de pobreza e para que evitem repassar essa situação para as próximas geraçóes. Além disso, é por meio desta dimensão que os indivíduos adquirem melhores oportunidades de emprego e, consequentemente, possibilidades de alcançar melhores níveis de qualidade de vida (UNESCO, 2014).

A quarta dimensão, Condição de Moradia, foi quantificada pela proxy presença de banheiro e água encanada no domicílio. Segundo o Banco Mundial (2000), a presença de banheiro (ou saneamento básico) é um fator primordial para evitar contaminaçóes e propagação de doenças que reduzem a qualidade de vida dos indivíduos ou, até mesmo, os levam à óbito. Essa dimensão relaciona-se estreitamente com a Saúde, uma vez que a melhoria nas condições de saneamento básico e no tratamento da água possui forte relação com a redução de doenças que provocam a mortalidade infantil.

\subsection{Procedimento econométrico}

Visando alcançar o objetivo proposto, utilizou-se o método econométrico de dados em painel, método que caracteriza-se por combinar dados cross-section com séries temporais, permitindo ao pesquisador analisar questôes que não poderiam ser exploradas com apenas um desses procedimentos (GREENE, 2008).

Dentre as vantagens de utilização desse método, uma delas consiste no poder de controlar a heterogeneidade dos indivíduos (caracterizados por países, empresas, entre outros) quando esses estão relacionados com o tempo. Os estudos que utilizam-se apenas de séries temporais ou somente de corte transversal, não levam em consideração tal heterogeneidade, produzindo, frequentemente, resultados fortemente viesados (BALTAGI, 2005). Além disso, os dados em painel trabalham com uma maior quantidade de informação, gerando dados mais informativos, com maior variabilidade e eficiência, menor colinearidade e maior número de graus de liberdade; são ainda, satisfatoriamente melhores quando aplicado ao estudo das dinâmicas de mudanças e aptos a mensurar efeitos não detectáveis nas análises de corte transversal e de séries temporais puras.

Quanto às heterogeneidades individuais, existem três modelos principais de dados em painel que podem controlá-las, são eles: o modelo de efeito fixo (EF), o modelo de efeito aleatório (EA) ou o modelo pooled. O modelo de efeito fixo objetiva controlar características muito particulares dos indivíduos que diferem entre os agentes mas que são invariantes no tempo, podendo influenciar as variáveis explicativas inclusas no modelo (GREENE, 2008). 
Para isso, supóe-se que o intercepto $\left(\beta_{0}\right)$ incorpora as variaçóes entre os indivíduos através da inclusão de variáveis dummys, enquanto, os parâmetros permanecem constantes tanto para os indivíduos quanto no tempo.

Já no modelo de efeito aleatório (EA), Gujarati (2006) destaca que o intercepto varia de um agente para outro, porém permanece constante ao longo do tempo, enquanto os parâmetros são constantes tanto para os indivíduos quanto no tempo. Assim, a diferença entre modelos de EF e EA, deve-se à forma de considerar o intercepto, enquanto o modelo de efeito fixo trata-o como um parâmetro fixo, o modelo de efeito aleatório refere-se ao intercepto como uma variável aleatória, ou seja, considera os agentes como amostras aleatórias de uma população de indivíduos (MONTE, 2016).

O terceiro modelo, Pooled, não possui heterogeneidade latente entre os indivíduos, ou seja, a amostra não possui características muito peculiares capazes de influenciar as variáveis explicativas (GREENE, 2008). Portanto, sob essas condições, utilizam-se dois: um modelo médio para a população e um de Mínimos Quadrados Ordinários (MQO), o melhor método para fornecer estimadores consistentes e eficientes.

A partir destas definiçóes, destaca-se que primeiramente é necessário realizar alguns testes para definir qual modelo adequa-se melhor. O teste Chow decide entre os modelos Pooled e Efeito Fixo; o teste Hausman indica se o modelo é de Efeito Aleatório ou de Efeito Fixo; e o teste LM de Breush-Pagan decide entre os modelos Pooled e Efeito Aleatório. O teste Wald especifica se o modelo é homocedástico ou heterocedástico, em caso de presença da heterocedasticidade, realiza-se o teste Hausman Robusto, uma vez que os testes anteriores tornam-se inválidos. Este teste definirá se o modelo será de Efeitos Aleatórios ou de Efeitos Fixos.

\subsection{O modelo econométrico}

A construção do modelo econométrico de dados em painel busca evidenciar as principais variáveis responsáveis pelo maior grau de privação dos indivíduos na perspectiva multidimensional da pobreza ao longo dos três últimos anos censitários. O modelo foi esquematizado de acordo com a base de dados municipais para as variáveis proxies de Pobreza, Saúde, Educação e Condições de Moradia para os estados de maior e menor IDH. A equação de regressão (1) foi estimada para cada estado e em seguida comparou-se os resultados a fim de entender como comportou-se os determinantes da pobreza multidimensional para Alagoas e São Paulo.

$$
\text { Pobreza }_{i t}=\beta_{0}+\beta_{1} \text { Renda }_{+}+\beta_{2} \text { lnSaúde }_{i t}+\beta_{3} \text { Educação }_{i t}+\beta_{4} \text { CondMoradia }_{i t}+\varepsilon
$$

Onde: Pobreza $=$ nível de pobreza, variável quantificada via proxy percentual de pobres com rendimento domiciliar per capita igual ou inferior a $\mathrm{R} \$ 140,00$ mensais; Renda= nível de renda, quantificada pela proxy Índice de Gini; $\operatorname{lnSaúde~=~acesso~à~saúde,~variável~}$ quantificada via proxy logarítmica de mortalidade infantil; Educaçáo = acesso à educação, variável quantificada via proxy taxa de analfabetismo da população de 15 anos de idade ou mais; CondMoradia = condiçóes de moradia; variável quantificada via proxy percentual da população que vive em domicílios com banheiro e água encanada; $\beta_{0}=$ coeficiente de 
inclinação do modelo ; $\boldsymbol{\varepsilon}=$ termo de erro. O subscrito "i” corresponde aos indivíduos, que no presente estudo são os municípios dos estados de Alagoas, com 102 unidades, e de São Paulo, com 645 unidades. O período de tempo "t" dos modelos será igual a 3, referente aos 3 anos dos censos coletados. O "n" para o estado de Alagoas é igual a 306 (102 x 3) e para o estado de São Paulo foi de 1935 (645 x 3).

Conforme descrito por Baltagi (2001), os modelos construídos possuem todas as observaçóes, ou seja, cada município alagoano e paulista é analisado em todos os períodos de tempo, portanto, o painel pode ser considerado balanceado. Salienta-se, ainda, que o modelo foi trabalhado no software Stata $10.0^{8}$.

\section{Análise de resultados}

Uma primeira análise descritiva acerca da evolução da porcentagem de pobres durante os anos dos censos considerados (1991, 2000 e 2010), constata-se que o estado de Alagoas, com menor IDH, sempre esteve acima da média do Brasil em relaçáo à porcentagem de pobres. Enquanto isso, São Paulo, estado com maior IDH, apresentou-se sempre abaixo dessa média, embora a proporção de pobres tenha diminuído ao longo do período em ambos os estados e no país em geral (FIGURA 2). Portanto, torna-se relevante identificar os múltiplos fatores que determinam a pobreza nessas localidades, visando contribuir para a elaboração de políticas públicas efetivas que busquem sua erradicação.

Figura 2 - Percentual de pobres nos anos de 1991, 2000 e 2010.

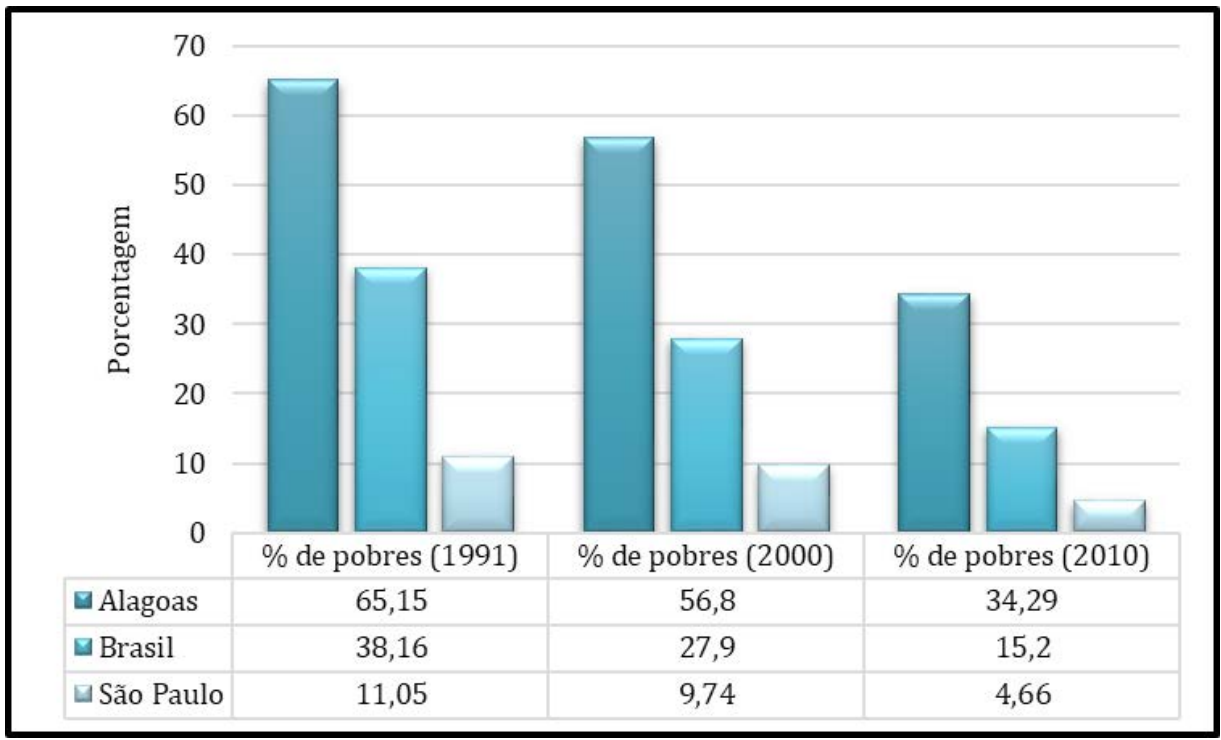

Fonte: Elaboração própria.

8 Licenciado para o Departamento de Economia e Relaçóes Internacionais da UFSM. 
Dessa forma, seguiu-se com a estimação de um modelo baseado nos estudos de Martins e Wink (2013), com o objetivo de encontrar uma relaçáo entre o percentual de pobres e as demais variáveis relacionadas às privaçóes sofridas pelos indivíduos ao longo dos anos censitários. As Tabelas 1 e 2, demonstram os resultados dos testes que determinam o modelo de dados em painel mais adequado para ambos os estados, a saber: pooled, Efeito Fixo ou Efeito Aleatório.

Tabela 1 - Testes de especificação do modelo de Alagoas

\begin{tabular}{|c|c|c|c|c|}
\hline \multirow{2}{*}{ Teste } & \multirow{2}{*}{ Diagnóstico } & \multirow{2}{*}{ Hipóteses do teste } & \multicolumn{2}{|c|}{ Alagoas } \\
\hline & & & Valor* & p-valor ${ }^{* *}$ \\
\hline Chow & $\begin{array}{c}\text { Testar o modelo Pooled contra } \\
\text { Efeito Fixo }\end{array}$ & $\begin{array}{l}\text { H0: Modelo Pooled } \\
\text { H1: Modelo de EF }\end{array}$ & 2,19 & 0,0000 \\
\hline $\begin{array}{c}\text { LM de } \\
\text { Breush-Pagan }\end{array}$ & $\begin{array}{c}\text { Testar o modelo Pooled contra } \\
\text { Efeitos Aleatórios }\end{array}$ & $\begin{array}{l}\text { H0: Modelo Pooled } \\
\text { H1: Modelo de EA }\end{array}$ & 17,06 & 0,0000 \\
\hline Hausman & $\begin{array}{c}\text { Testar o modelo Efeitos } \\
\text { Aleatórios contra Efeitos Fixos }\end{array}$ & $\begin{array}{l}\text { H0: Modelo de EA } \\
\text { H1: Modelo de EF }\end{array}$ & 36,22 & 0,0000 \\
\hline Wald & Heterocedasticidade & $\begin{array}{c}\text { H0: ausência de } \\
\text { heterocesdasticidade } \\
\text { H1: Presença de } \\
\text { heterocedasticidade }\end{array}$ & 21285,30 & 0,0000 \\
\hline $\begin{array}{l}\text { Hausman } \\
\text { Robusto }\end{array}$ & $\begin{array}{c}\text { Testar o modelo Efeitos } \\
\text { Aleatório contra Efeitos Fixo }\end{array}$ & $\begin{array}{l}\text { H0: Modelo de EA } \\
\text { H1: Modelo de EF }\end{array}$ & 14,46 & 0,0060 \\
\hline
\end{tabular}

Fonte: Elaboração própria.

Nota: *valor estatístico do teste; ${ }^{* *}$ p-valor é a probabilidade de o valor estatístico do teste ser maior do que o valor observado, ou seja, é a probabilidade de não rejeição da hipótese nula $\left(H_{0}\right)$. Para um teste obter significância estatística é necessário que seu valor seja menor que 0,1 .

Analisando-se, primeiramente, o modelo mais indicado para o estado de Alagoas, verificou-se pela Tabela 1 que todos os testes rejeitaram a hipótese nula a $1 \%$ de significância, isso ocorre pois o p-valor estatístico foi menor do que 0,01. Desse modo, a análise do teste Chow e do teste Hausman, revelou Efeitos Fixo como o melhor modelo, uma vez que rejeitam as hipóteses $H_{0}$ de modelo pooled e EA, respectivamente. Já o teste $L M$ de Breush-Pagan, indicou que o melhor modelo seria o de efeito aleatório, pois o p-valor obtido $(0,0000)$ indica a rejeição de H0 do modelo pooled. Seguiu-se, entáo, para o teste Wald, que revelou a presença de heterocedasticidade no modelo ao rejeitar a hipótese nula $H_{0}$ a $1 \%$ de nível de significância ( $\mathrm{p}$-valor $=0,0000$ ). Visto isso, realizou-se o teste Hausman robusto, que determinou, finalmente, o modelo de Efeito Fixo como o mais adequado ao rejeitar $H_{0}$ a 1\% de significância estatística ( $\mathrm{p}$-valor $=0,0060)$. 
Tabela 2 - Testes de especificação do modelo de São Paulo

\begin{tabular}{|c|c|c|c|c|}
\hline \multirow{2}{*}{ Teste } & \multirow{2}{*}{ Diagnóstico } & \multirow{2}{*}{ Hipóteses do teste } & \multicolumn{2}{|c|}{ Sáo Paulo } \\
\hline & & & Valor* & p-valor** \\
\hline Chow & $\begin{array}{c}\text { Testar o modelo Pooled contra } \\
\text { Efeito Fixo }\end{array}$ & $\begin{array}{l}\text { H0: Modelo Pooled } \\
\text { H1: Modelo de EF }\end{array}$ & 2,25 & 0.0000 \\
\hline $\begin{array}{c}\text { LM de } \\
\text { Breush- } \\
\text { Pagan }\end{array}$ & $\begin{array}{c}\text { Testar o modelo Pooled contra } \\
\text { Efeitos Aleatórios }\end{array}$ & $\begin{array}{l}\text { H0: Modelo Pooled } \\
\text { H1: Modelo de EA }\end{array}$ & 136,95 & 0.0000 \\
\hline Hausman & $\begin{array}{c}\text { Testar o modelo Efeitos } \\
\text { Aleatórios contra Efeitos Fixos }\end{array}$ & $\begin{array}{l}\text { H0: Modelo de EA } \\
\text { H1: Modelo de EF }\end{array}$ & 78,77 & 0.0000 \\
\hline Wald & Heterocedasticidade & $\begin{array}{l}\text { H0: ausência de } \\
\text { heterocesdasticidade } \\
\text { H1: Presença de } \\
\text { heterocedasticidade }\end{array}$ & 5,8107 & 0.0000 \\
\hline $\begin{array}{l}\text { Hausman } \\
\text { Robusto }\end{array}$ & $\begin{array}{l}\text { Testar o modelo Efeitos } \\
\text { Aleatório contra Efeitos Fixo }\end{array}$ & $\begin{array}{l}\text { H0: Modelo de EA } \\
\text { H1: Modelo de EF }\end{array}$ & 49,42 & 0.0000 \\
\hline
\end{tabular}

Fonte: Elaboração própria.

Nota: *valor estatístico do teste; ${ }^{* *}$-valor é a probabilidade de o valor estatístico do teste ser maior do que o valor observado, ou seja, é a probabilidade de não rejeição da hipótese nula $\left(H_{0}\right)$. Para um teste obter significância estatística é necessário que seu valor seja menor que 0,1 .

Posteriormente, analisou-se os resultados dos testes para o estado de Sáo Paulo expostos na Tabela 2, onde, também, encontrou-se que todos os testes rejeitaram a hipótese nula a $1 \%$ de significância (p-valor $<0,01)$. Os testes Chow e Hausman indicam o modelo de Efeito Fixo como o mais adequado, enquanto o teste $L M$ de Breush-Pagan considerou como melhor modelo o de Efeito Aleatório. Através do teste Wald, revelou-se a presença de heterocedasticidade, o que encaminhou para a realização do teste Hausman robusto, que indicou como melhor modelo final o de Efeito Fixo.

Como para ambos estados o resultado final de melhor modelo a ser estimado foi de dados em painel sobre Efeito Fixo com a presença de heterocedasticidade, necessitou-se sanar tal problema através da estimação via erro padrão robusto. Nas Tabelas 3 e 4 estão dispostos os resultados dessa estimação para Alagoas e São Paulo, respectivamente. 
Tabela 3 - Resultados da estimação do modelo para o estado de Alagoas

\begin{tabular}{lc}
\hline \multirow{4}{*}{ Variável Explicativa } & Variável Dependente \\
\cline { 2 - 2 } & \% DE POBRES \\
AL & $(\mathrm{ep})$ \\
p-valor
\end{tabular}

Fonte: Elaborado pelos autores.

Nota: Modelo estimado conforme equação 1; (ep) são os erros-padrão robustos, que demonstram a variação da média amostral em relação a amostral; p-valor é a probabilidade de o valor estatístico do teste ser maior do que o valor observado, ou seja, é a probabilidade de não rejeição da hipótese nula $\left(H_{0}\right)$. Para um teste obter significância estatística é necessário que seu valor seja menor que 0,$1 ;{ }^{* * *}$ Modelo significativo a $1 \%$ de nível de significância;

A partir dos resultados encontrados na Tabela 3 para o estado de Alagoas, observa-se que os parâmetros de todas as variáveis foram significativos a $1 \%$ (ou seja, p-valor < 0,01), indicando que todas as dimensôes analisadas explicam os níveis de pobreza no estado de Alagoas, a saber: Renda, Saúde, Educação e Condiçóes de Moradia. Ademais, observou-se, através da estimação, que todos os coeficientes das variáveis explicativas obtiveram os sinais esperados exposto anteriormente no Quadro 1.

Sendo todas as variáveis significativas, pôde-se realizar a interpretação de todos os parâmetros das dimensóes consideradas como influências para a pobreza dita multidimensional. Através da Tabela 3 para o estado de Alagoas, observa-se que o aumento de 0,1 no Índice de Gini, contribui para o aumento percentual de pobres em aproximadamente 52,47 pontos percentuais. Já o aumento de $1 \%$ na Mortalidade Infantil, 
está associado à expansão de cerca de 8,6 pontos percentuais na porcentagem de pobres. Além disso, o aumento de 1 ponto percentual na Taxa de Analfabetismo leva ao crescimento de aproximadamente 0,70 pontos percentuais na porcentagem de pobres; e o acréscimo de 1 ponto percentual na porcentagem de Domicílios com Banheiro e Água Encanada está relacionado ao declínio de 0,24 pontos percentuais na porcentagem de pobres.

Tabela 4 - Resultados da estimação do modelo para o estado de São Paulo

\begin{tabular}{|c|c|}
\hline & Variável Dependente \\
\hline Variável Explicativa & $\begin{array}{c}\text { \% DE POBRES } \\
\text { SP } \\
\text { (ep) } \\
\text { p-valor } \\
\end{array}$ \\
\hline Constante & $\begin{array}{c}14,33428^{* * *} \\
(3,835883) \\
\mathbf{0 , 0 0 0}\end{array}$ \\
\hline Renda & $\begin{array}{c}55,03773^{* * *} \\
(4,593866) \\
\mathbf{0 , 0 0 0} \\
\end{array}$ \\
\hline lnSaúde & $\begin{array}{c}0,1271135^{* * *} \\
(0.0472667) \\
\mathbf{0 . 0 0 7}\end{array}$ \\
\hline Educação & $\begin{array}{c}1,088181^{\text {*** }} \\
(0,0622207) \\
\mathbf{0 . 0 0 0}\end{array}$ \\
\hline CondMoradia & $\begin{array}{c}-0,4271404^{* * *} \\
(0,0285758) \\
\mathbf{0 . 0 0 0}\end{array}$ \\
\hline $\mathrm{R}^{2}$ within & 0,8064 \\
\hline $\mathrm{R}^{2}$ between & 0,7051 \\
\hline $\mathrm{R}^{2}$ overall & 0,7586 \\
\hline Observaçôes & 1935 \\
\hline
\end{tabular}

Fonte: Elaborado pelos autores.

Notas: Modelo estimado conforme equação 1; (ep) são os erros-padrão robustos, que demonstram a variação da média amostral em relação a amostral; p-valor é a probabilidade de o valor estatístico do teste ser maior do que o valor observado, ou seja, é a probabilidade de não rejeição da hipótese nula $\left(H_{0}\right)$. Para um teste obter significância estatística é necessário que seu valor seja menor que 0,1 ; ${ }^{* * *}$ Modelo significativo a $1 \%$ de nível de significância;

Ao observar-se a significância dos parâmetros das variáveis independentes do modelo relativo ao estado de São Paulo, agregados na Tabela 4, vê-se que todos foram significativos a $1 \%$ (p-valor $<0,01)$. Assim, os níveis de pobreza desse estado é explicado tanto pela dimensão Renda como pelos parâmetros das demais dimensóes: Saúde, Educaçáo 
e Condições de Moradia. Além disso, ressalta-se que os sinais dos coeficientes das variáveis explicativas corresponderam aos esperados, presentes no Quadro 1.

A interpretação do modelo descrito na Tabela 4, indica que, para o estado de São Paulo, o aumento de 0,1 no Índice de Gini, gera uma elevação no percentual de pobres em, aproximadamente, 55,04 pontos percentuais. Quanto à Taxa de Mortalidade Infantil, seu aumento em $1 \%$, acresce, em aproximadamente, 0,13 pontos percentuais a porcentagem de pobres. Além disso, a observação da Taxa de Analfabetismo possui uma relação positiva com com a pobreza, seu coeficiente sugere que um aumento de 1 ponto percentual nessa taxa eleva o percentual de pobres em, aproximadamente, 1,09 pontos percentuais. Por fim, a observação das Condiçóes de Moradia indica que o aumento de 1 ponto percentual na porcentagem de Domicílios com Banheiro e Água Encanada, reduz a porcentagem de pobres em cerca de 0,43 pontos percentuais.

Ao comparar-se os resultados obtidos na estimação dos modelos, nota-se que os fatores que afetam os níveis de pobreza são similares nos estados de Alagoas e São Paulo, ou seja, todas as dimensóes estão relacionadas com o percentual de pobres das duas localidades, apesar de serem estados com graus de desenvolvimento humano táo discrepantes. Percebese, ainda, que o coeficiente da dimensão Saúde, medida pela proxy mortalidade infantil, foi maior no estado de Alagoas, enquanto o coeficiente das proxys das demais dimensóes (Renda, Educação e Condições de Moradia), que são: índice de gini, taxa de analfabetismo e percentual da população que vive em domicílios com banheiro e água encanada, respectivamente, foram maiores no estado de São Paulo.

Desta forma, os resultados obtidos ratificam o pensamento de Sen (2013) de que os níveis de renda são importantes para a variação dos graus de pobreza, porém não é somente por dimensóes monetárias que as privaçóes devem ser quantificadas, existem outros fatores como a educação, a saúde e as condições de moradia, aqui quantificados, que são capazes de influenciar os níveis de pobreza, confirmando seu caráter multifacetado.

Os achados deste estudo também corroboram com trabalhos nacionais e internacionais que tratam da pobreza como fenômeno multidimensional. As análises de Betti e Verma (1999) também demonstram que a pobreza suplementar (que incorpora dimensóes não monetárias como saúde, emprego, habitação, entre outros) apresenta maior intensidade que a pobreza monetária, mostrando que a observação de tal fenômeno de um ângulo unidimensional torna-se restrita e incompleta. Da mesma forma, Martins e Wink (2013) vão ao encontro dos resultados aqui expostos, seus estudos demonstraram uma forte relação entre os níveis da pobreza e o acesso às dimensóes educação, saúde e saneamento.

Portanto, assim como na análise de Sen (2013), a pobreza não pode ser tratada de forma unidimensional, suas características revelam que trata-se de um fenômeno de caráter multifacetado, como encontrado neste estudo e também nos trabalhos de Diallo (2012), Wang e Wang (2016), Ximenes et al. (2016), Fahel, Teles e Caminhas (2016), Santos e Villatoro (2018), Martins et al. (2019) e entre outros. 


\section{Conclusáo}

No presente trabalho pretendeu-se averiguar os fatores, além da renda, que são determinantes da pobreza multidimensional nos estados de maior e menor IDH do Brasil. A investigação foi realizada via análise econométrica de dados em painel para os últimos três anos censitários (1991, 2000 e 2010), considerando as dimensóes: Renda, Educação, Saúde e Condiçôes de Moradia.

A análise descritiva demonstrou que o estado de Alagoas, detentor do menor IDH do Brasil, possui grande porcentagem de pobres, estando acima da média nacional em todos os anos analisados. Por outro lado, o estado de São Paulo, que possui o maior IDH do Brasil, revelou uma porcentagem de pobres sempre abaixo da média nacional durante o período observado. Essa primeira análise demonstrou a existência de uma grande relação entre o nível de desenvolvimento humano e os graus de pobreza desses estados, o que deu margem para a estimação posterior que buscou captar os determinantes, além da renda, da pobreza na abordagem multidimensional.

A investigação seguinte dos determinantes das privaçóes de cada um dos estado via modelo de dados em painel, concordou com perspectivas anteriores de que a pobreza náo deriva somente da renda. Em Alagoas e São Paulo, detectou-se que as dimensões: Saúde, Educação e Condiçóes de Moradia foram significativas e, portanto, também repercutem as privaçóes dos indivíduos. O coeficiente relacionado à dimensão Saúde quantificada pela proxy mortalidade infantil foi maior para o estado de Alagoas, enquanto os demais coeficientes das proxys de Renda, Educação e Condiçóes de Moradia, que são, respectivamente: índice de gini, taxa de analfabetismo e percentual da população que vive em domicílios com banheiro e água encanada, foram maiores no modelo referente ao estado de São Paulo.

Em ambos os estados, a pobreza revelou o mesmo caráter multidimensional, apesar de serem locais de níveis de desenvolvimento humano tão discrepantes. Esses resultados indicaram que o alcance de níveis mais elevados de desenvolvimento humano requer dos governantes e demais dirigentes, uma preocupação com políticas públicas que visem além da melhoria dos padróes de renda dos indivíduos. $\mathrm{O}$ combate às privaçóes humanas deve buscar melhorias no acesso a serviços de saúde, educação, condições de moradia e entre outros fatores sociais e humanos além daqueles quantificados nos modelos aqui expostos.

Desse modo, encerra-se este estudo ressaltando como sua principal limitação, mas que não invalida os resultados encontrados, a falta de uma série de dados histórica mais extensa, uma vez que o período apenas censitário impede uma melhor visualização dos determinantes da pobreza. Ademais, recomenda-se para trabalhos futuros, tanto a expansão desta análise para todos os estados brasileiros, a fim de averiguar se os determinantes de pobreza se mantêm os mesmos nas demais localidades do Brasil, como uma análise da pobreza multifacetada para os países com maior e menor IDH do mundo. 


\section{REFERÊNCIAS}

ALKIRE, S.; OLDIGES, C.; KANAGARATNAM, U. Multidimensional poverty reduction in India 2005/6-2015/16: still a long way to go but the poorest are catching up. Reino Unido, 2018.(Research in progress series, 54a )

ATLAS DO DESENVOLVIMENTO HUMANO, 2015. Disponível em: <http://www. atlasbrasil.org.br/2013/pt/consulta/>. Acesso em: 01 jun. 2017.

BALTAGI, B. Econometric Analysis of Panel Data. Chichester: John Wiley and Sons, 2005.

CARDOSO, A. L. Indicadores sociais e políticas públicas: algumas notas críticas.

Proposta, v. 77, p. 42-53, 1998.

CARVALHO, J. M. Cidadania no Brasil: o longo caminho. Rio de Janeiro: Civilização Brasileira, 2002.

CODES, A. L. M. A Trajetória do pensamento científico sobre pobreza: em direçáo a uma visão complexa. Brasília: IPEA, 2008. (Textos para discussão no 1332).

CRESPO, A. P. A.; GUROVITZ, E. A Pobreza como um Fenômeno Multidimensional. RAE - Eletrônica, v. 1, n.2, p. 1-12, 2002.

DIALLO, F. Analysing multidimensional poverty in guinea: a fuzzy set approach. AERC Research Paper 251. Nairobi: African Economic Research Consortium, 2012.

FAHEL, M.; TELES, L. R.; CAMINHAS, D. A. Para além da renda: "uma análise da pobreza multidimensional no brasil". Revista Brasileira de Ciências Sociais, São Paulo, v. 31, n. 92, 2016.

GRAZIANO, S. J. Quem precisa de uma estratégia de desenvolvimento?. In: GRAZIANO, S. J.; MARC, J.; BIANCHINI, V. O Brasil rural precisa de uma estratégia de desenvolvimento. Brasília: Ministério do Desenvolvimento Agrário / Conselho Nacional de Desenvolvimento Rural Sustentável / Núcleo de Estudos Agrários e Desenvolvimento Rural, 2001. p. 5-52

GREENE, W. H. Econometric analysis. Estados Unidos: Person Prentice Hall. 2008.

GIL, A. C. Como elaborar um projeto de pesquisa. 4. Ed. São Paulo: Atlas, 2009.

GUIMARÃES, J. R. S.; JANNUZZI, P. M. IDH, Indicadores Sintéticos e Suas Aplicaçôes. Uma Análise Crítica. Revista Brasileira de Estudos Urbanos e Regionais, v. 7, n. 1. p. $73-90,2005$.

GUJARATI, D. N. Econometria básica. Rio de Janeiro: Elsevier-Campus, 2006. 
HICK, R. Poverty as Capability Deprivation: Conceptualising and measuring poverty in contemporary Europe. European Journal of Sociology, v. 55, n. 3, p. 295 - 323. 2014.

INSTITUTO DE PESQUISA ECONÔMICA APLICADA (IPEA). Comunicado 58: dimensão, evolução e projeção da pobreza por região e por estado no Brasil. Brasília, jul. 2010 .

MARTINS, C. H. B.; WINK JUNIOR, M. Pobreza extrema em municípios do Rio Grande do Sul: evidências da multidimensionalidade. Porto Alegre: Secretaria do Planejamento, Gestão e Participação Cidadã. Fundação de Economia e Estatística Siegfried Emanuel Heuser, 2013. (Textos para Discussão FEE no 114)

MARTINS, H. M. O. M.; GOMES, S. A.; GOMES, R. L.; PIRES, M. M. Análise da pobreza sob a ótica multidimensional nos municípios de Itabuna e Ilhéus, Bahia. Revista Brasileira de Gestáo e Desenvolvimento Regional, v. 15, n. 1, 2019.

MARTINI, R. A. et al. Um ensaio sobre os aspectos teóricos e metodológicos da economia da pobreza. Belo Horizonte: UFMG/Cedeplar, 2009. (Texto para Discussão no 369).

MESTRUM, F. Mondialisation et pauvreté: de l'utilité de la pauvreté dans le nouvel ordre mondial. Paris: L'Harmattan, 2002.

MUNDIAL, B. Luta contra a pobreza. Relatório sobre o desenvolvimento mundial, v. 2001, 2000.

NAÇÓES UNIDAS. Relatório Sobre os Objetivos de Desenvolvimento do Milénio. New York: Nações Unidas, 2015. Disponível em: <https://www.unric.org/pt/images/ stories/2015/PDF/MDG2015_PT.pdf>. Acesso em: 03 ago. 2017.

ORGANIZAÇÃO DAS NAÇŌES UNIDAS PARA A EDUCAÇÃO, A CIÊNCIA E A CULTURA (UNESCO). Relatório de Monitoramento Global de EPT 2013/2014. Ensinar e Aprender: alcançar a qualidade para todos.

ORSI, R. A. Reflexóes sobre o desenvolvimento e a sustentabilidade: o que o IDH e o IDHM podem nos mostrar?. 2009. $171 \mathrm{f}$. Tese (Doutorado em Geografia) - Programa de Pós-Graduação em Geografia, Universidade Estadual Paulista, Rio Claro, 2009.

PROGRAMA DAS NAÇÓES UNIDAS PARA O DESENVOLVIMENTO (PNUD). Human Development Report 2010: The Real Wealth of Nations - Pathways to Human Development. New York: Oxford University Press, 2010.

ROMÂO, M. E.C. Considerações sobre o conceito de pobreza. Revista Brasileira de Economia, Rio de Janeiro, v. 36, n. 4, p. 355-370, 1982. 
ROMERO, J. A. R. Analise espacial da pobreza municipal no estado de minas gerais 1991 - 2000. In: Encontro Nacional de Estudos Populacionais, 14., 2006, Caxambú. Anais... Caxambú: ABEP, 2006. p. 1 - 19.

SALAMA, P.; DESTREMAU, B. O tamanho da pobreza: economia política da distribuição de renda. Petrópolis: Ed. Garamond, 2001.

SANTOS, M. E.; VILLATORO, P. A multidimensional poverty index for Latin America. Review of Income and Wealth, v. 64, n. 1, p. 52-82, 2018.

SEN, A. O desenvolvimento como expansão de capacidades. Lua Nova, n. 28-29, p. 313$334,1993$.

SEN, A. Desenvolvimento como liberdade. Editora Schwarcz S.A: São Paulo, 2013.

TOWNSEND, P. Introduction, Compendium of best practices in poverty measurement. Expert Group on Poverty Statistics (Rio Group), Rio de Janeiro, September, 2006.

UNITED NATIONS CHILDREN'S FUND (UNICEF). Committing to Child Survival: A Promise Renewed. Progress Report 2013. United Nations Plaza, New York, NY 10017, USA, 2013.

UNITED NATIONS DEVELOPMENT PROGRAMME (UNDP). Towards an 'Energy Plus' approach for the poor. 2011.

VAZ, A. C. N.; SILVA, Y. C. Análise do IDH-M e possibilidades de aprimoramento para captaçáo mais apurada dos efeitos das políticas de desenvolvimento social. Secretaria de Avaliação e Gestão da Informação - SAGLI, Ministério do Desenvolvimento Social e Combate à Fome. Estudo técnico, n. 20, 2013.

WANG, Y.; WANG, B. Multidimensional poverty measure and analysis: a case study from Hechi City, China. SpringerPlus, v. 5, n. 1, p. 642, 2016.

XIMENES, V. M. et al. Pobreza multidimensional e seus aspectos subjetivos em contextos rurais e urbanos nordestinos. Estudos de Psicologia, v. 21, n. 2, p. 146-156, 2016. 